
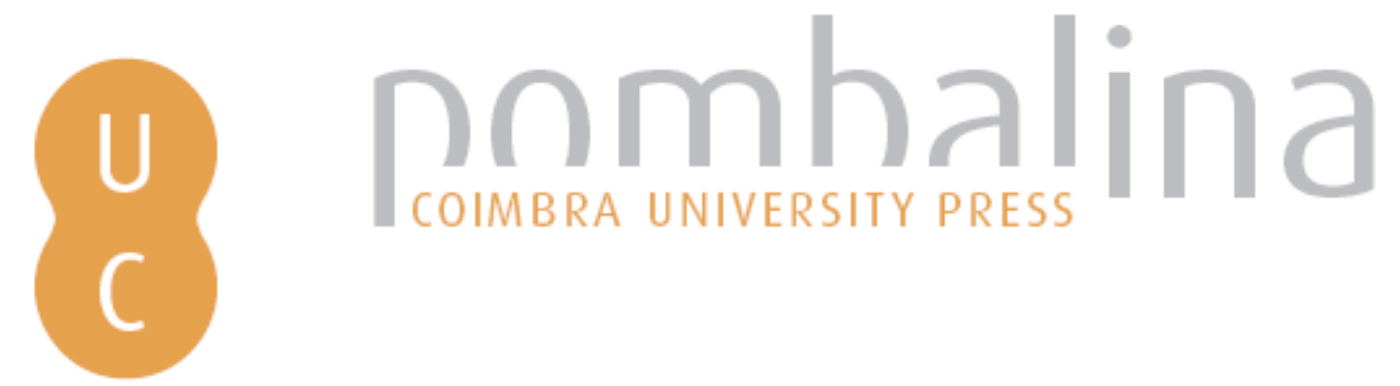

\title{
Brasileiros em Coimbra, Coimbra nos brasileiros: viagem e torna-viagem da Univer(C)idade na literatura
}
Autor(es):
Ribeiro, Maria Aparecida
Publicado por: Imprensa da Universidade de Coimbra
URL
persistente:
URI:http://hdl.handle.net/10316.2/30716
DOI:
DOI:http://dx.doi.org/10.14195/978-989-26-0308-7_7
Accessed : $\quad$ 26-Apr-2023 14:09:47

A navegação consulta e descarregamento dos títulos inseridos nas Bibliotecas Digitais UC Digitalis, UC Pombalina e UC Impactum, pressupõem a aceitação plena e sem reservas dos Termos e Condições de Uso destas Bibliotecas Digitais, disponíveis em https://digitalis.uc.pt/pt-pt/termos.

Conforme exposto nos referidos Termos e Condições de Uso, o descarregamento de títulos de acesso restrito requer uma licença válida de autorização devendo o utilizador aceder ao(s) documento(s) a partir de um endereço de IP da instituição detentora da supramencionada licença.

Ao utilizador é apenas permitido o descarregamento para uso pessoal, pelo que o emprego do(s) título(s) descarregado(s) para outro fim, designadamente comercial, carece de autorização do respetivo autor ou editor da obra.

Na medida em que todas as obras da UC Digitalis se encontram protegidas pelo Código do Direito de Autor e Direitos Conexos e demais legislação aplicável, toda a cópia, parcial ou total, deste documento, nos casos em que é legalmente admitida, deverá conter ou fazer-se acompanhar por este aviso.

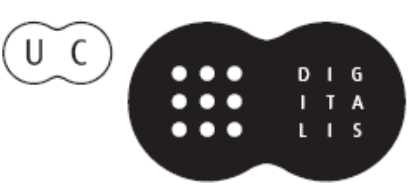



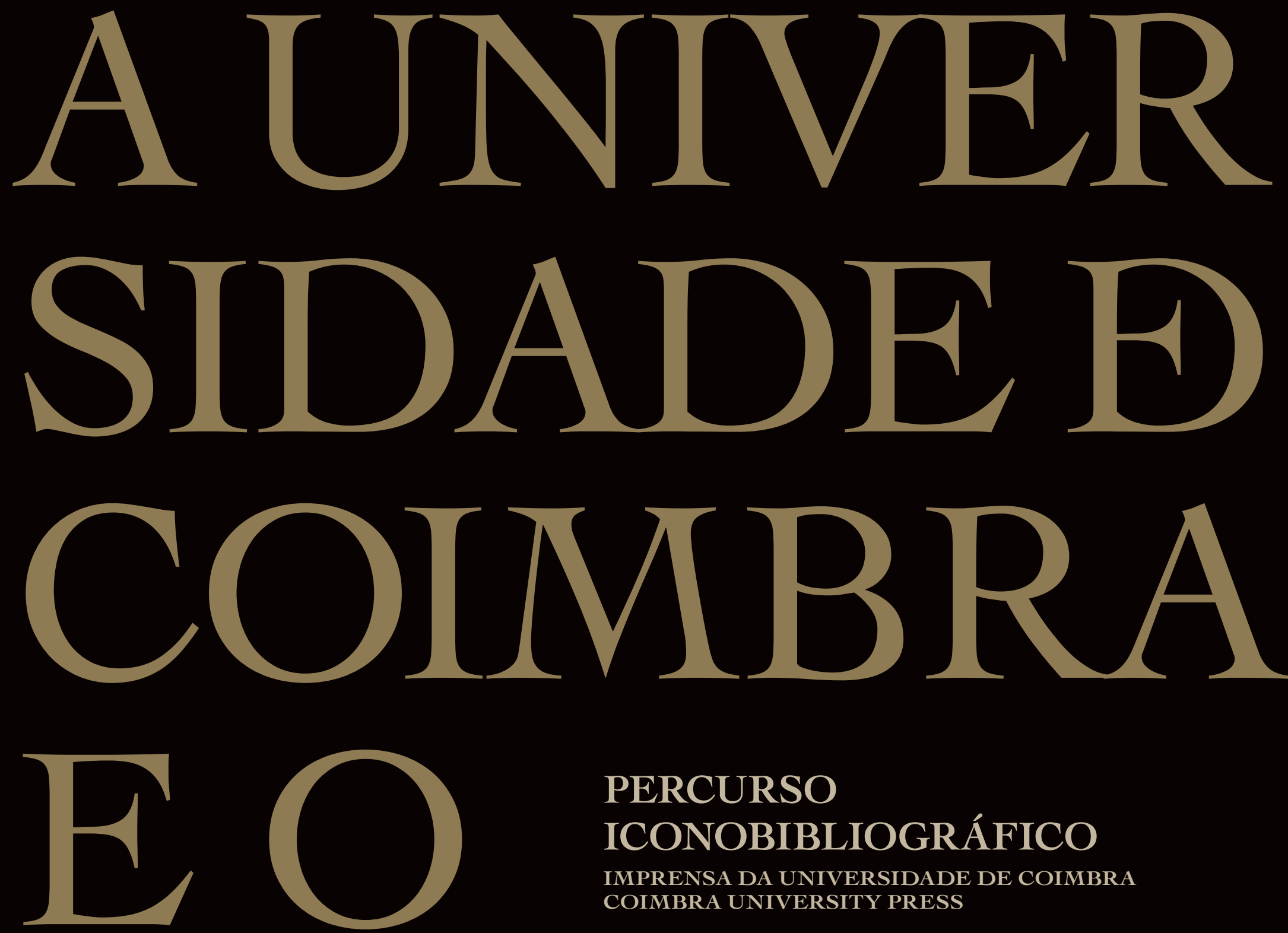

\section{PERCURSO}

\section{ICONOBIBLIOGRÁFICO}

IMPRENSA DA UNIVERSIDADE DE COIMBRA

COIMBRA UNIVERSITY PRESS

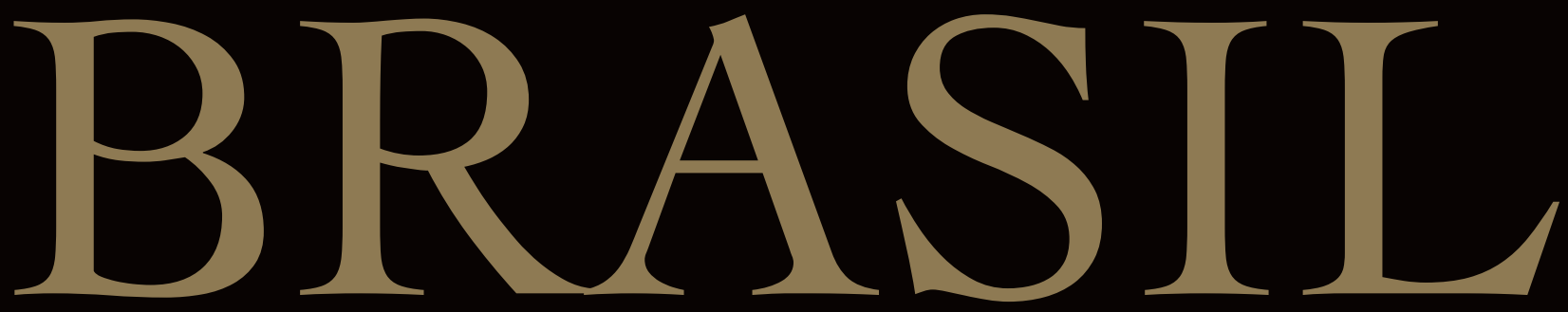


EDIÇÃO

Imprensa da Universidade de Coimbra

EMAIL: IMPRENSAUC@CI.UC.PT

URL: HTTP://WWW.UC.PT/IMPRENSA_UC

VENDAS ONLINE: HTTP://WWW.LIVRARIADAIMPRENSA.COM

Coordenação Científica

José Pedro Paiva

José Augusto Cardoso Bernardes

Textos

Joño Gabriel Silva

José Pedro Paiva

José Augusto Cardoso Bernardes

Joaquim Romero Magalhães

Décio Ruivo Martins

Fernando Ramos

Lúcio CunHa

Rui JaCINTO

JoÃo Arriscado Nunes

Maria Aparecida Ribeiro

Investigação e Conteúdos das Fichas Catalográficas

A.E. Maia do Amaral (Bguc)

Ana Maria Leitão Bandeira (auc)

Créditos Fotográficos

Miguel Pacheco/Redinteg Lda. (Digitalizações de livros e documentos)

Gilberto Pereira (exemplares zoológicos)

Pedro Casaleiro (exemplar etnográfico)

Tiago Maia/AuC (PeÇas museológicas - Ma)

Delfim Ferreira (arquitetura)

DESIGN

António Barros

INFOGRAFIA

Carlos Costa

EXECUÇÃo GRÁFICA

NORPRINT

ISBN

978-989-26-0161-8

Depósito Legal

Obra Publicada com o Patrocínio de 

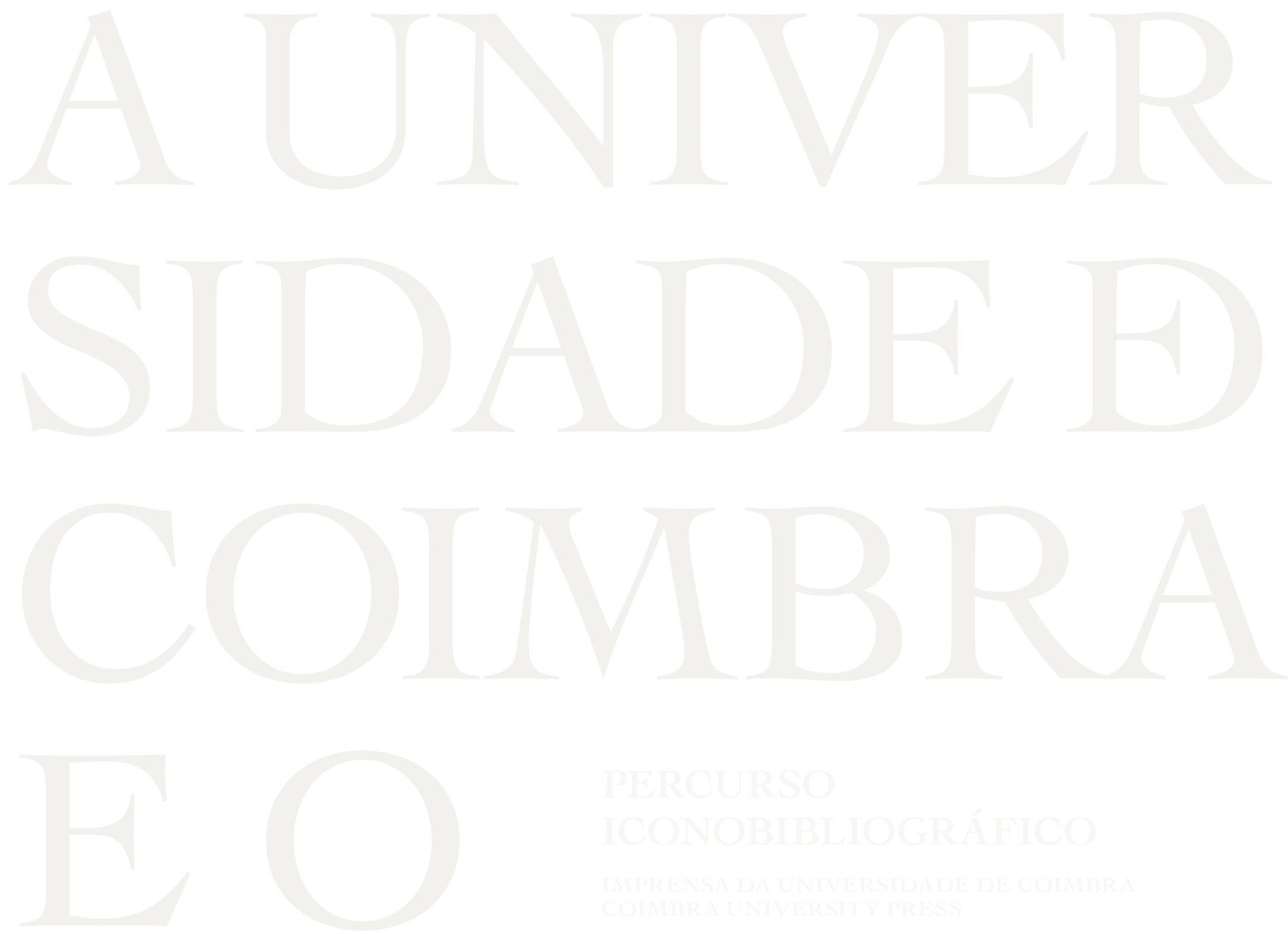

PRTOUROO
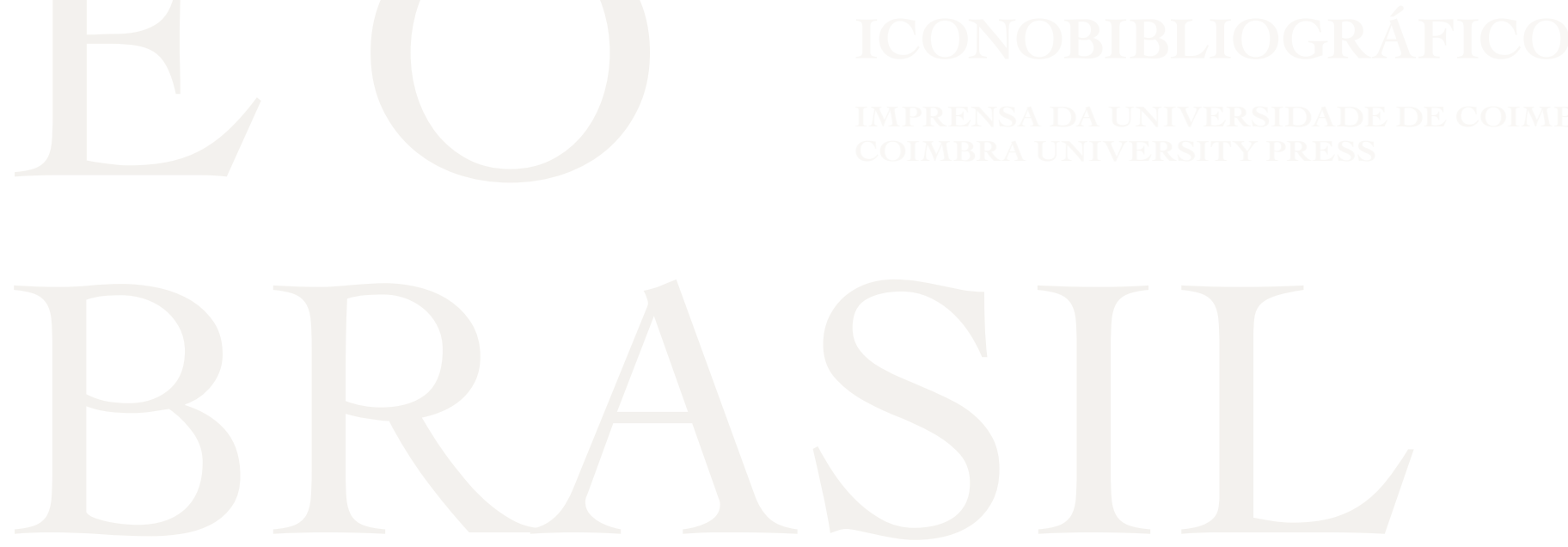
(Página deixada propositadamente em branco) 


\section{Brasileiros EM COIMBRA, CoImbra nos Brasileiros \\ viagem e torna-viagem da Univer (C)idade na literatura}




associados: primeiramente em função do nome daquele Frei Henrique, franciscano que, participante da frota de Cabral, celebrou a primeira missa. Depois, ainda no século XVI, porque de Coimbra partiria o "Apóstolo do Brasil", José de Anchieta, que iria escrever o primeiro poema épico da América, o De Gestis Mendi de Saa, contando os feitos do $3^{\circ}$ Governador Geral do Brasil, irmão do poeta Sá de Miranda. Mais tarde, ainda por via dos jesuítas, os primeiros brasileiros (índios conversos, como os entendeu Gonçalves Dias) serviriam de motivo na decoração dos altares barrocos da Sé Nova.

Em 1577, vieram morar em Coimbra filhos de portugueses, nascidos no Brasil, para frequentar a Universidade, que começou, de forma sistemática e inconteste, a influir na formação da intelligentzia brasileira, nos seus mais diferentes aspetos: Leis, Cânones, Matemáticas, Medicina... Eram esses estudantes oriundos principalmente de Permabuco, Bahia, São Paulo, Rio de Janeiro, perfazendo, até 1914, duas mil novecentos e sessenta e sete matrículas, às quais se podem somar ainda os quarenta e quatro nomes que só figuram nos livros de Atos e Graus.

Muitos desses alunos tornaram-se poetas celebrados e Coimbra marcou-lhes a poesia na forma, no tema ou como lugar de referência. Outros ficaram conhecidos por suas criações, como o santista Bartolomeu de Gusmão, pioneiro do balão de ar quente - a "Passarola", que o popularizou como "Padre Voador"; o carioca António José da Silva, dramaturgo supliciado pela Inquisição, que Bernardo Santareno, séculos mais tarde, fez protagonizar O Judeu; ou Lucas Junot, o santista estudante de Matemática, criador do "Fado de Santa Clara". Outros ainda deixaram suas marcas de maneira coletiva, como na igreja do Colégio Mariano de São José (hoje Hospital Militar), onde ainda se pode ler:
"ESTA CAPELLA MANDARAM FAZER A SUA CUSTA OS ESTUDANTES ULTRAMARINOS DA BAHYA EM O ANNO DE 1728".

Também alguns brasileiros, ex-alunos ou não, em número bem menor, chegaram a exercer cargos na Universidade, como Frei José de Santa Rita Durão, que ensinou Teologia; Vicente Seabra, que lecionou Química; José Bonifácio de Andrada e Silva, o "Patriarca da Independência" do Brasil, primeiro professor de Metalurgia; D. Francisco de Lemos, Reitor que, no tempo de Pombal, procedeu à Reforma da Universidade, fato, aliás, necessário, na visão de outro brasileiro, Manuel Inácio da Silva Alvarenga, o árcade Alcino Palmireno, no poema herói cômico O Desertor (1772).

Tão forte foi a imagem de Coimbra no Brasil que passou a ser natural lá estudarem algumas personagens literárias. Aluísio de Azevedo, no romance $O$ Mulato, a obra inaugural do Naturalismo no Brasil, mostra Coimbra como o lugar para onde um pai português com recursos mandou estudar o filho Raimundo. Também um dos avós de Brás Cubas, personagem de Machado de Assis, estudou na velha Universidade. Era o filho do tanoeiro Damião Cubas, que, enriquecido no Brasil, mandara o filho Luís Cubas para Coimbra. Mesmo o Modernismo não deixou de referir a cidade. Ribeiro Couto, por exemplo, em "Serena Coimbra", associa, embora não originalmente, o mito da cidade a outro que também marca a cultura brasileira - o mito de Camões.

Com a criação da Sala do Brasil, em 1925 - para o que colaboraram alunos brasileiros —, a sua reinauguração, em 1937 - numa iniciativa política dos governos de Getúlio Vargas e de Salazar - , e, finalmente, a criação da cadeira de Literatura Brasileira pela Reforma Galvão Teles (Decreto 
41.341/1957 de 30 de outubro), que a tornou obrigatória, muitos professores brasileiros foram contratados para lecionar na Faculdade de Letras da UC. Entre eles, Guilhermino César, um dos "Modernistas de Cataguases", que divulgou Coimbra entre os brasileiros, em suas crônicas para um jornal gaúcho e incorporou a cidade em sua poesia, mostrando, como os poetas brasileiros ex-alunos da Universidade, esse fluxo e refluxo, de padrões estéticos e sentimentos que aqui, embora de forma breve, se pretende exemplificar.

Se a literatura brasileira nasce assinalada pelo Barroco, tem também a marca de Coimbra, pois é nela que se formam dois de seus mais conhecidos poetas - Manuel Botelho de Oliveira e Gregório de Matos. Em contrapartida, porém, apresenta as primeiras manifestações de nativismo. Se Botelho de Oliveira incorporou os padrões estéticos aprendidos (até para mostrar que "as luzes do entendimento" não haviam sido negadas à “antiga habitação de índios incultos"), no poema "À Ilha de Maré" pareceu querer vingar-se, louvando ufano a exuberância tropical e chegando a dizer que ao pé das laranjas baianas as de Portugal "são primas dos limões, todas azedas" (Oliveira, 1953: t. 1, p. 43 e 128).

Foi também nos nove anos passados em Coimbra, para formarse em Cânones, conforme atestam os documentos existentes no Arquivo da Universidade, que Gregório de Matos aprendeu a dicção barroca e incorporou temas como o da limpeza de sangue e o do desconcerto do mundo, que desenvolveu tomando como base a realidade brasileira, como nos mostram sonetos do gênero dos que escreveu "Aos Caramurus da Bahia", romances como "Senhora Dona Bahia", ou versos como os dos "Epílogos", em que "torna a definir o poeta os maus modos de obrar na governança da Bahia
[…" (Mattos, 1989: 387). É, aliás, de acordo com essa dicção, branca, portuguesa, colonial, que os termos de origem tupi ou africana, incorporados à língua portuguesa, aparecem ao serviço do ludismo, como objetos exóticos. E embora a crítica brasileira, em sua maior parte queira fazer de Gregório de Matos um poeta original, porque sua "Boca do Inferno" se dirige muitas vezes à autoridade portuguesa, a sátira, que é a ponta de lança dessa crítica, era bastante cultivada pelos poetas barrocos portugueses e tinha por alvo os mais controversos assuntos. É natural, pois, que o poeta baiano, criticasse o povo e as autoridades de sua terra natal, motivado não propriamente pelo espírito nativista, mas por uma tendência das poéticas da época. Em função delas, usa imagens da cidade, para satirizar um seu oposto e parente, o Padre Dâmaso da Silva, vigário de N. Sra. do Loreto, "grande conimbricense, /sem jamais pôr pé em Coimbra”, fazendo-lhe assim o retrato: "A boca desempenada / é a ponte de Coimbra,/ onde não entram, nem saem, mais que mentiras" (Mattos, 1989: 359 e 358). Ou descreve o estudante de Coimbra, como:

Mancebo sem dinheiro, bom barrete,

Medíocre o vestido, bom sapato

Meias velhas, calção de esfola-gato,

Cabelo bem penteado, bom topete;

Presumir de dançar, cantar falsete, Jogo de fidalguia, bom barato, Tirar falsídia ao Moço do seu trato,

Furtar a carne à ama, que promete; A putinha aldeã achada em feira, Eterno murmurar de alheias famas, Soneto infame, sátira elegante; 
Cartinhas de trocado para a Freira,

Comer boi, ser Quixote com as damas,

Pouco estudo, isto é ser estudante. (Mattos, 1989: 95).

No século XVIII, um número bem maior de brasileiros bebeu em Coimbra a poética por que se iriam pautar. Entre eles, alguns dos que estiveram envolvidos na chamada Inconfidência Mineira, como Cláudio Manuel da Costa, que se formaria em 1753. Participante da vida da cidade e da Universidade, escreveu ele em Coimbra o "Epicédio consagrado à saudosa memória do Reverendissimo Senhor Fr. Gaspar da Encarnação, reformador dos Cônegos Regulares de Santo Agostinho da Congregação de Santa Cruz de Coimbra”, publicado no Real Colégio das Artes da Companhia de Jesus, em 1753; o "Culto métrico" (1749) e o "Munúsculo métrico" (1751), ambos poemas de louvor: o primeiro a uma Abadessa do Mosteiro de Figueiró, D. Teresa Clara de Jesus Evangelista, e o segundo a D. Francisco da Anunciação, Reitor da Universidade de Coimbra, a quem também o "Epicédio" foi oferecido. Mas não parou aí: nos "Apontamentos" que enviou à Academia Brasílica dos Renascidos da Bahia, que o havia convidado para sócio extranumerário, Glauceste Satúrnio (nome árcade de Cláudio) faz menção a outras composições escritas em Coimbra, onde publicou as suas Obras (1768), na Oficina de Luís Seco Ferreira. Embora seja esse livro considerado o marco do início do Arcadismo no Brasil, pelos poemas que se pautam pelo estilo simples, o próprio autor reconhece que algumas das composições nele contidas ainda seguem o estilo sublime, gosto coimbrão predominante em seus primeiros tempos de estudante, quando os padrões estéticos do Barroco ainda tinham grande $\operatorname{voga}^{1}$. Com tantas referências a Coimbra, não é de estranhar que lembrasse o Mondego e suas ninfas, como padrões estéticos de beleza e perfeição em várias ocasiões:

1 Cláudio desculpa-se pela "elegância" com que são ornados alguns poemas, pelo "muito uso de metáforas", dizendo que a maior parte foi composta em Coimbra, "ou pouco depois [...] tempo em que Portugal apenas rincipiava melhorar de gosto nas belas letras"
Enfim te hei de deixar, doce corrente

Do claro, do suavíssimo Mondego;

Hei de deixar-te enfim; e um novo pego

Formará de meu pranto a cópia ardente.

De ti me apartarei; mas bem que ausente,

Desta lira serás eterno emprego;

E quanto influxo hoje a dever-te chego,

Pagará de meu peito a voz cadente.

Das Ninfas, que na fresca, amena estância

Das tuas margens húmidas ouvia,

Eu terei sempre n’alma a consonância;

Desde o prazo funesto deste dia

Serão fiscais eternos da minha ânsia

As memórias da tua companhia” (COSTA, 1996: 80).

É em consonância com os padrões árcades de simplicidade e equilíbrio proclamados nesses versos, que o poeta nega, em "Para terminar a Academia", poder haver, entre os brasileiros, sensibilidade estética: "Uns gênios educados em um tão bárbaro país, em um país acostumado mais a ouvir os rugidos das feras que a harmonia das Musas, como poderiam produzir cadências que fossem dignas de chegar a uns ouvidos que se criaram entre a delicadeza, ao concerto?" (COSTA, 1996: 340)

Contudo, como nos poetas que o antecederam, o amor da Pátria é um incentivo e as Musas acabam por auxiliá-lo no canto do que é feio para os padrões árcades:

Não permitiu o céu que alguns influxos, que devi às águas do Mondego, se prosperassem por muito tempo: e destinado a buscar a Pátria, que, por espaço de cinco anos, havia deixado, aqui entre a grosseria dos seus génios, que menos pudera eu fazer, que entrega-me ao ócio e sepultar-me na ignorância! [...] Não são estas as venturosas praias da Arcádia; onde o som das 
águas inspirava a harmonia dos versos. Turva e feia a corrente destes ribeiros primeiro que arrebate as ideias de um Poeta deixa de ponderar a ambiciosa fadiga de minerar a terra que lhes tem pervertido as cores. A desconsolação de não poder subestabelecer aqui as delícias do Tejo, do Lima e do Mondego me fez entorpecer o engenho dentro do meu berço; mas nada bastou para deixar de confessar a seu respeito a maior paixão. Esta me persuadiu a invocar muitas vezes, e a escrever a Fábula do Ribeirão do Carmo, rio o mais rico desta Capitania que corre, e dava o nome à Cidade de Mariana, minha Pátria, quando era Vila. (COSTA, 1996: 47)

Um ano depois de Cláudio Manuel da Costa haver-se formado em Leis, iniciava os seus estudos em Teologia na Universidade, um outro mineiro, Frei José de Santa Rita Durão. Agostiniano, amigo de Frei Manuel do Cenáculo e de D. Francisco de Lemos, ele ocuparia, depois de vários problemas que o obrigaram a fugir de Portugal, o lugar de lente na Universidade, onde proferiu, em 1778, a Pro annua studiorum instauratione oratio.

O perfil literário de Durão não foge muito aos dos outros estudantes brasileiros: a incorporação da vida da cidade e a tentativa de falar do Brasil, ainda que em moldes europeus. Do primeiro caso, são exemplo os setenta e cinco hexâmetros em latim macarrônico da "Descrição da Função do Imperador de Eiras que se costuma fazer todos os anos em o Mosteiro de Celas junto a Coimbra, dia do Espírito Santo" ${ }^{2}$. Do segundo, o célebre Caramuru: poema épico do descobrimento da Babia, que, segundo os biógrafos de Durão, teria sido escrito em Coimbra, às margens do riacho Cuselhas, e que tanta fama alcançou a ponto de ser objeto das atenções de Ferdinand Denis e de vários outros autores franceses do século XIX, além de ponto de partida para inúmeras releituras de escritores (entre os quais o português João de Barros), músicos, pintores e cineastas.

2 Manuscrito existente na Biblioteca Geral da Universidade de Coimbra, estudado por Mendes dos Remédios em "Alguma coisa de novo sobre Santa Rita Durão”, Revista de Língua Portuguesa (dir. Laudelino Freire), Rio de Janeiro, 1920, v. VI, p. 69-82
Nas "Reflexões Prévias e Argumento" do Caramuru, o poeta não deixa dúvidas quanto à sua fidelidade afetiva ao Brasil: “Os sucessos do Brasil não mereciam menos um Poema que os da Índia. Incitou-me escrever este o amor da pátria" (DURÃO, 1781: 3). O texto, porém, obedece formalmente ao melhor padrão camoniano (dez cantos, 834 estrofes em oitava rima, 6672 versos decassílabos heroicos), embora em nenhum momento a mitologia pagã tenha lugar no poema. Mas, se para além desse aspeto formal, leva ainda a marca de Camões numa releitura da "Máquina do Mundo", coexistem com esse aspeto, a enumeração e a exploração do sensorial de sabor barroco representam, um dos traços do hibridismo da obra que, no entanto, não foge ao realismo iluminista pelo fundamento histórico, pelas notas indicativas das fontes do poema, e mesmo pela supressão do maravilhoso.

O herói da epopeia é Diogo Álvares Correia, a quem os índios chamaram Caramuru, isto é, "fillho do trovão", por ter usado uma arma de fogo. Português, cristão, homem do século XVI cujo suporte histórico é um colono naufragado nas costas da Bahia, antes da chegada do $1^{\circ}$ governador geral, Tomé de Sousa, Diogo Álvares representa a expansão da fé e do império.

Ao ver Paraguaçu, filha de um cacique do recôncavo baiano e prometida de Gupeva, outro chefe indígena, por ela se apaixona, o mesmo acontecendo à índia. Diogo logo promete casamento à índia, mas, continuando a exercer o papel de catequista que, desde o primeiro encontro com os selvagens caracterizou o seu perfil, diz que não terá com ela nenhuma relação carnal enquanto não for batizada. Ora isto só ocorre na França, depois de uma longa viagem em que o português fala ao rei francês das grandezas da colônia e recebe dele a proposta de ficar, no Brasil, mas ao seu serviço, o que Diogo não aceita (ficando ainda mais nítido no seu perfil de colonizador, o projeto colonial do poema).

Paraguaçu, além de "princesa" indígena, o que já lhe confere um caráter excecional, é diferente da "gente tão nojosa" (veja-se como o narrador classifica os índios): além de não ter atitudes lascivas como as outras índias, é pudica (ela aparece vestida de algodão e cora diante de Diogo) e "de cor tão alva como a branca 
neve” (e o que não era neve "era de rosa”) ${ }^{3}$. De comum com sua raça, Paraguaçu tem apenas a coragem e a bravura, com que luta ao lado de Diogo, contra Jararaca e seus companheiros.

O heroísmo de Caramuru consiste, pois, em resistir à luxúria, ensinar aos selvagens os preceitos do catolicismo, propagandear no estrangeiro as riquezas da colónia de Portugal e mostrar fidelidade a seu rei, não aceitando ficar ao serviço do rei da França. Mas não para aí: é ele quem, afinal, ao fazer Paraguaçu batizar-se e ao casar-se catolicamente com ela, transforma-a em Catarina Álvares, a herdeira indígena que, em função de sua nova fé, adota um novo rei, D. João III, que faz aclamar e a quem cede as terras do Brasil e suas riquezas, através de Tomé de Sousa, o novo Governador Geral.

O poema épico de Santa Rita Durão mantém a visão colonial: os índios são maus, feios, de costumes abomináveis; o Brasil deve ser cristianizado e submetido ao rei de Portugal. Como nas cartas e relatos dos cronistas, apesar dos extensos louvores à terra fértil, sua gente é inculta. Embora o poema contenha um dado novo - o amor entre um português e uma índia - este não está ao serviço da fundação da nacionalidade brasileira. Os "sucessos do Brasil”, que não merecem menos que os da Índia, são sucessos de Portugal.

A imagem de Coimbra, como símbolo de padrão a seguir, começou a perder espaço com a Independência do Brasil e com a propagação das ideias românticas. Mas ainda assim estudar em Coimbra era o que faziam os filhos de portugueses, pois que a universidade brasileira engatinhava e, às vezes, era mais fácil chegar à Europa que deslocar-se no próprio Brasil. Foi o caso do maranhense Gonçalves Dias, que em maio de 1838, partiu para Portugal, acompanhado de um ferreiro que voltava à terra.

Em Coimbra, matriculou-se ele no Colégio das Artes e viveu primeiro na casa do padre Bernardo Joaquim Simões de Carvalho. Em 1840, começou a frequentar a Universidade indo

3 Cf. Caramuru: poema épico do descobrimento da Babia, II, 78. morar nos Palácios Confusos e a seguir, na Rua do Correio. Em 1841, Gonçalves Dias entrou em contacto com o grupo da Gazeta Literária, dirigida por José Freire de Serpa Pimentel. Mais tarde, fez parte da redação de O Trovador, que João de Lemos e outros estudantes lançaram. O medievismo de Gonçalves Dias, cuja composição mais notória são as "Sextilhas de Frei Antão", escritas já no Brasil e que giram em torno de uma figura pertencente à Idade Média - Gonçalo Hermigues - e de duas já da Idade Moderna - a Princesa Santa Joana e o rei D. João II —, vem possivelmente dessa época.

Mas as "Sextilhas" não foram o primeiro poema de Gonçalves Dias marcado pelo medievismo próprio dos românticos. O seu Primeiros Cantos (1847), saudado por Alexandre Herculano como “a verdadeira poesia nacional do Brasil” (Dias, 1959: 98), reunia, para além de composições indianistas, outras, onde o gosto pela Idade Média se fazia sentir, quer nos temas quer no próprio vocabulário.

Nos Segundos Cantos, publicados em 1848, juntamente com as "Sextilhas" não se pode deixar de ver na "Donzela" que divagava na praia, alguém que suspira pelo amado junto às ondas (cf. "Rosa no Mar!") como nas cantigas de Martim Codax, nem tão pouco em "Queixumes" os ecos de outras cantigas de amigo. Relacionado com a exploração literária dos temas medievais, surge o filão da presença moura na Península, "não como elemento exterior e exótico, mas como constituinte da identidade portuguesa" (Ramalhete, 1996: 67), de que António de Serpa Pimentel, amigo de Gonçalves Dias, foi o maior e melhor cultor. O poeta brasileiro não deixa de perseguir também esta tendência: "Zulmira" é um exemplo.

O medievismo bebido em Coimbra, permanece até nos Últimos Cantos, combinado até com os temas indianistas: em "Leito de Folhas Verdes", em que alguns críticos chegam a ver uma alba, uma índia espera em vão pelo amado Zatir, enquanto o dia clareia, emitindo um canto em nada dessemelhante aos das donzelas cujo amigo tinha ido à guerra.

Mas a cultura bebida em Coimbra não deixou no maranhense apenas marcas medievistas, nem Gonçalves Dias levou dela apenas 
gratas lembranças, como as que certamente lhe ficaram da visão dos saveiros enfeitados com flores e folhas que navegaram pelo Mondego, no festejo que, em 1841, deram os estudantes brasileiros para celebrar a coroação do Imperador Pedro II (em honra de quem o poeta escreveu o seus primeiros versos); ou do banquete na Lapa dos Esteios, durante o qual João de Lemos, Serpa Pimentel, Lisboa Serra e o próprio Gonçalves Dias declamaram; ou ainda quando andou de namoro com uma moça de Formoselhas. Se os anos de 1842 e 1843, foram férteis em termos de produção literária, o poeta — já que a madrasta lhe não enviava do Brasil a mesada necessária para continuar os estudos - teve de viver da boa vontade alheia, como se vê nesta carta que escreveu ao conterrâneo e amigo Teófilo de Carvalho Leal, datada de 28 de setembro de 1843 :

Aqui estou, meu amigo, nesta terra maldita e aporrinhada - maldita de quanta poesia há no mundo - e aporrinhada de quantas aporrinhações podem aporrinhar um cristão. As aulas dizem que abrem no dia 9 e que estão à espera de S.S.M.M. - Ora parece-me que nem aulas nem majestades me farão demorar aqui por muito tempo - Venho ver se acabo com o meu saldo - e dentro de 4 até 5 dias - estarei ou não decidido continuar por este ano com meus estudos - O que me pesa é ser este o ano do bacharel [...] Um homem - pobre - e desconhecido - assenta-se nas escadas de um palácio - ou no adro de uma igreja, nu e esfarrapado - e ninguém atenta no que ali jaz. [...] A mim já isso não me pode acontecer — sem vergonha.[...] Na Figueira tenho guarida certa e gostosa - mas tanto me têm feito que pedir mais seria descaramento - Terras há ainda onde eu poderia ficar - mas para isso seria preciso pedir. (DIAS, 1959: 797)

Talvez tenha sido esse estado de alma que, juntamente com o espírito romântico, motivasse Gonçalves Dias, em julho de 43, a glosar os versos de Goethe ${ }^{4}$, escrevendo a célebre "Canção do

4 Kennst du das Land, wo die Citronen blüben, / Im Junkeln Laub die Goldorangen glühen [...] / Kennst du es wohl? - Dahin, Jabin! / Moecht' ich...ziehn
Exílio", da qual alguns versos viriam figurar no Hino Nacional Brasileiro. Nela, diferentemente da ironia de Gregório, da reverência de Cláudio ou das observações jocosas de Durão, Coimbra surge com uma natureza de cores amesquinhadas. Sem sabiá e sem palmeiras, várzeas menos floridas, com um céu menos estrelado, a cidade é o cá menos prazenteiro que se opõe ao Brasil, um lá idealizado.

Mais de um século depois, outra seria a visão, mas também a condição, do mineiro Guilhermino César. Indicado por Costa Pimpão, que o conhecera no Rio Grande do Sul, ficaria de 1962 a 1965, seria contratado pela Universidade para reger a cadeira de Literatura Brasileira, mas acabaria por lecionar também História do Brasil e o Seminário de Literatura Brasileira. Em 1967, Guilhermino César voltaria a Coimbra, para receber, no dia 14 de maio, o título de Doutor Honoris Causa, e retomar a lecionação apenas da Literatura Brasileira, no ano letivo de 1968-1969. Ficaria até 1970.

Muitos dos colegas e ex-alunos de Guilhermino dizem que era um professor afável, um colega espirituoso e criador de palavras, uma pessoa onde "o poeta" [...] discretamente convive com o investigador", como notou o Doutor Walter de Medeiros, um "homem de trabalho ao contrário de outros professores brasileiros que tinham vindo do Brasil apenas para passear" (MEDEIROS, 1968: 37) ou, em observação mais fina, como a do Doutor Morujão ao fazer-lhe o elogio como candidato a Doutor Honorid Causa pela Universidade de Coimbra, Guilhermino era "o brasileiro que, apagando muitos mal-entendidos, foi o embaixador discreto e eficaz da sensibilidade e inteligência das Terras de Santa Cruz" (MORUJÃO, 1968: 31). Em suma: alguém de quem Coimbra gostou.

Mas o mais interessante de todos os depoimentos sobre Guilhermino ocorreu durante um desses fantásticos acasos que a vida nos prepara. Numa noite de alguma chuva e certo frio, numa tertúlia ao ar livre em Viana do Castelo, em que fui discutir Literatura Brasileira, eis que da assistência surge uma voz feminina 
que conhecia a obra de, nada mais nada menos, que Alphonsus de Guimaraens (se coisa rara entre brasileiros, que dizer entre portugueses?). Havia feito a sua tese de Licenciatura precisamente sobre esse poeta. O orientador? “Um querido!” - dizia ela - "o Doutor Guilhermino”. Era Maria da Conceição Campos.

Quem compulsa os livros de sumário de Guilhermino César observa quão diferente dos que o antecederam (e até dos que o sucederam) foi a sua atuação na Universidade. Além da discussão de tópicos importantes da literatura brasileira, o professor preocupou-se em, de ano para ano, ir aprimorando os programas, ora ampliando o número de autores focados, (196364), ora dedicando um maior número de aulas ao Barroco e ao ufanismo (1964-65), ora ainda proporcionando aos alunos, no $1^{\circ}$ semestre, uma visão panorâmica da Literatura Brasileira, desde os cronistas até ao Concretismo, à instauração Práxis, e Guimarães Rosa, para, no $2^{\circ}$ semestre, instituir um curso monográfico, sobre "o romantismo nacional e popular", onde o autor de Iracema receberia especial atenção, e dedicar várias aulas ao Regionalismo, a Machado de Assis, a Carlos Drummond de Andrade (1969-70).

Além dessas marcas palpáveis da sua passagem pela Universidade de Coimbra, Guilhermino deixou outras — as suas publicações: 'Dona Fernanda, a gaúcha do Quincas Borba', em "O Instituto"; 'O messianismo político, no Brasil, e Alexandre Herculano', na "Brasilia”; Lira Coimbrã e Portulano de Lisboa, dado à estampa pela Livraria Almedina, e outras, ligadas à literatura portuguesa.

Lira Coimbrã mostra a relação que o poeta Guilhermino manteve com a cidade e "paisagem granulada" ("Mondegovia" in: CÉSAR, 1965: 36), relação cujo lado pitoresco (embora também por vezes lírico) ele deixou para as crônicas que publicou no Correio de Povo, de Porto Alegre. Coimbra o "leva / ao cativeiro desta imagem espetada / na areia, no chão, no galo de ferro da igreja, / no Caramulo, distante, - o que resta de azul e doce I na total aridez" ("Na Couraça dos Apóstolos” in: CÉSAR, 1965: 22). Em Coimbra, ele reescreve a gonçalvina "Canção do Exílio", sem a romântica idealização do Brasil, mas igualmente cheia de intensidade afetiva. A amizade com Miguel Torga leva-o a São Martinho de Anta, que lhe merece poema com epigrafe tirada de "I-Juca-Pirama!" e onde celebra o autor de Bichos (A Torga, aliás, serão mais tarde dedicados dois artigos no Correio do Povo, um dos quais de extrema importância, por mostrar a "antena crítica" de Guilhermino César ${ }^{5}$ ). Em Coimbra, a poesia sempre esperada ("a poesia chegará", diz ele num "Bilhete para Cataguases") ancora inúmeras vezes no tema da tradição e da morte. Mas a memória de Coimbra, que ecoa nas crónicas escritas em Porto Alegre, é a de um "cartão postal", de "uma cidade extática", onde as "janelas do casario se alternam como numa construção só, planejada por um Brueghel bêbado", de "uma pirâmide surrealista salpicada de janelas - caranguejos arranhando a face do tempo" (CÉSAR, 4/9/1971). O cartão-postal tem, porém, "poderes ocultos" de transformar-se a cada hora do dia, e marcos vários, que o cronista domina e descreve. Entre eles, o restaurante Ó Adelino, merecedor de uma crônica que o dono do estabelecimento mandou imprimir "para oferecer aos seus clientes e amigos" (CÉSAR, 1967). Outro, a Universidade, dominando "a colina", sempre olhada com respeito, "no esplendor (eterno!) que lhe cabe na partição geral dos bens" (CÉSAR, 4/9/1971), e que o fez Doutor Honoris Causa.

Guilhermino foi um marco na literatura brasileira lecionada na Universidade de Coimbra, Coimbra foi um marco na vida de Guilhermino. Coimbra gostou de Guilhermino, Guilhermino gostou de Coimbra. Mas Cataguases foi sempre a sua origem e o seu destino: "Morrer aqui / como um peixe / morre e sobe / à flor das águas / velhas / do Mondego" ("Morrer aqui” in: César, 1965: 97), foi, apenas, uma hipótese. O importante era ser "bem digerido / Pelo chão de Cataguases, reino de Minas, Brasil" ("Viagem" in: César,1965: 97). Daí que, ao supor "morrer aqui", em Coimbra, ele quisesse morrer de "olhos pregados neste rio que me leva / a um largo (e suas árvores) em Cataguases." ("Morrer aqui" in: César,1965: 97).

5 Cf. 'A Criação do Mundo', Correio do Povo, “Caderno de Sábado”, 20/5/1972. 
Fonte de saber, necessidade, mito, dura realidade cotidiana, a Universidade de Coimbra assinalou a cultura brasileira durante quatro séculos, tornou-se um mito, e foi ganhando algumas marcas (talvez poucas) dos brasileiros que por aqui passaram. Hoje, continua ela a receber brasileiros, não só nos cursos de Mestrado e Doutoramento, mas, desde 2010, em números maciços, em função do Programa de Licenciaturas Internacionais. Os alunos deste programa já começaram a marcar a sua presença, criando, em 2011, a Semana Cultural Brasileira, para mostrar a Coimbra o Brasil como um mosaico de culturas. Em 2012, integrando-a na Semana Cultural da Universidade, procuram eles agora reforçar essa visão e alargá-la: a partir do mote "Navegar é preciso", lançado pela Reitoria, alunos e professores brasileiros e de outras nacionalidades promoverão palestras, oficinas, exposições e espetáculos em torno da glosa "Viagens do Carnaval".

\section{Referências bibliográficas}

CÉSAR, Guilhermino, Lira Coimbrã e Portulano de Lisboa, Coimbra, Livraria Almedina, 1965.

CÉSAR, Guilhermino, Da 'Arte de Viver' (transcrição do jornal brasileiro Zero Hora), Nova Casa Minerva, 1967 (edição de Ó Adelino)

CÉSAR, Guilhermino, 'Janelas de Coimbra”, Correio do Povo, "Caderno de Sábado", 4/9/1971.

CÉSAR, Guilhermino, 'A Criação do Mundo', Correio do Povo, "Caderno de Sábado”, 20/5/1972.

COSTA, Cláudio Manuel da. In: Domício Proença Filho (org.) A Poesia dos Inconfidentes. Poesia Completa de Cláudio Manuel da Costa, Tomás Antônio Gonzaga e Alvarenga Peixoto, Rio de Janeiro, Nov Aguilar, 1996, p. 41-530.

DIAS, Gonçalves, Poesia Completa e Prosa Escolbida, Rio de Janeiro, Ed. José Aguilar, 1959.

DURÃO, Fr. José de Santa Rita, Caramuru, Poema Épico do Descobrimento da Babia, Lisboa, Régia Officina Typográfica, 1781.

MATTOS, Gregório de. Se Souberas Falar Também Falaras. Antologia Poética (org., sel., estudo e notas, Gilberto Mendonça Teles) Lisboa, Imprensa Nacional - Casa da Moeda, 1989.

MEDEIROS, Walter de Sousa, "Elogio do Apresentante, Doutor Álvaro Júlio da Costa Pimpão”, Boletim do Gabinete Português de Leitura, n¹2, Porto Alegre, 1968.

MORUJÃO, Alexandre Fradique de Oliveira, "O Elogio do Doutor Guilhermino César”, Boletim do Gabinete Português de Leitura, nº 12, Porto Alegre, 1968.

OLIVEIRA, Manuel Botelho, Música do Parnasso. Rio de Janeiro, M.E.C. I Instituto Nacional do Livro, 1953, t.1. (ed. org. por Antenor Nascentes). 


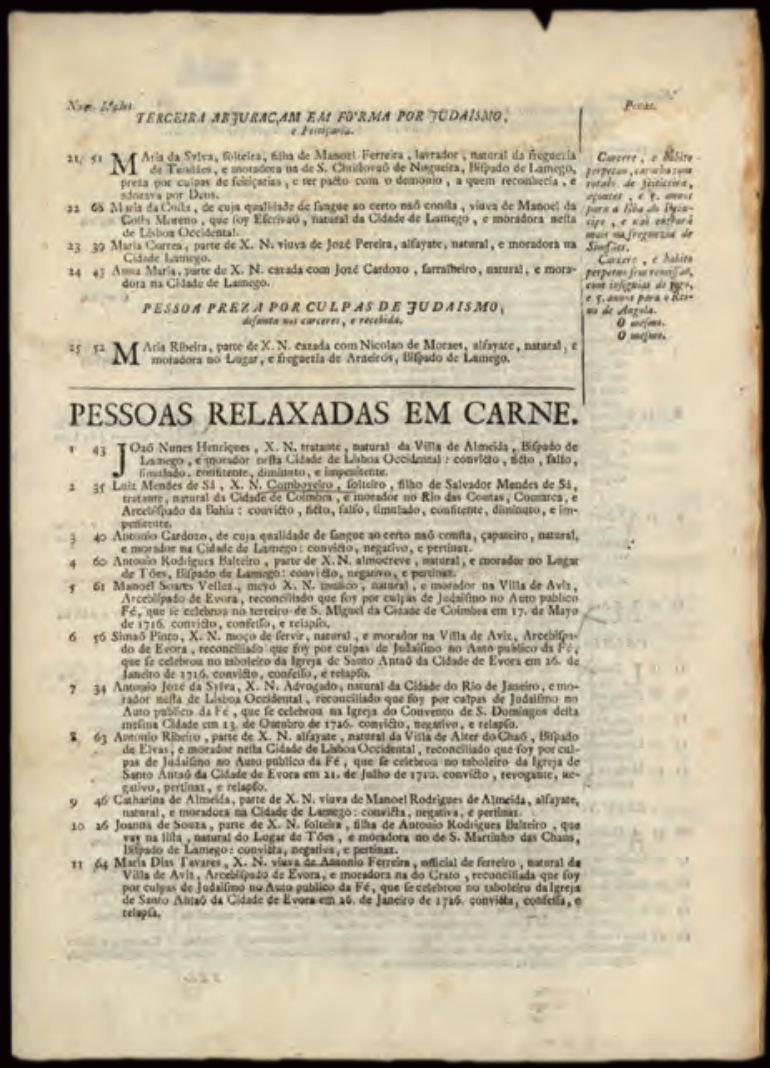

Página da publicação onde, entre muitos outros condenados pela Inquisição, consta o nome do relaxado António José da Silva "advogado, natural do Rio de Janeiro". Lista das pessoas, que sabiram, condenacóes, que tiveram, e sentenças,

que se léraó no Auto publico da Fé, que se celebrou na Igreja do Convento de S. Domingos desta cidade de Lisboa occidental em domingo 18 de outubro de 1739 ... - [S.1.: s.n., 1739?] BGUC: V.T.-15-10-3(5) 


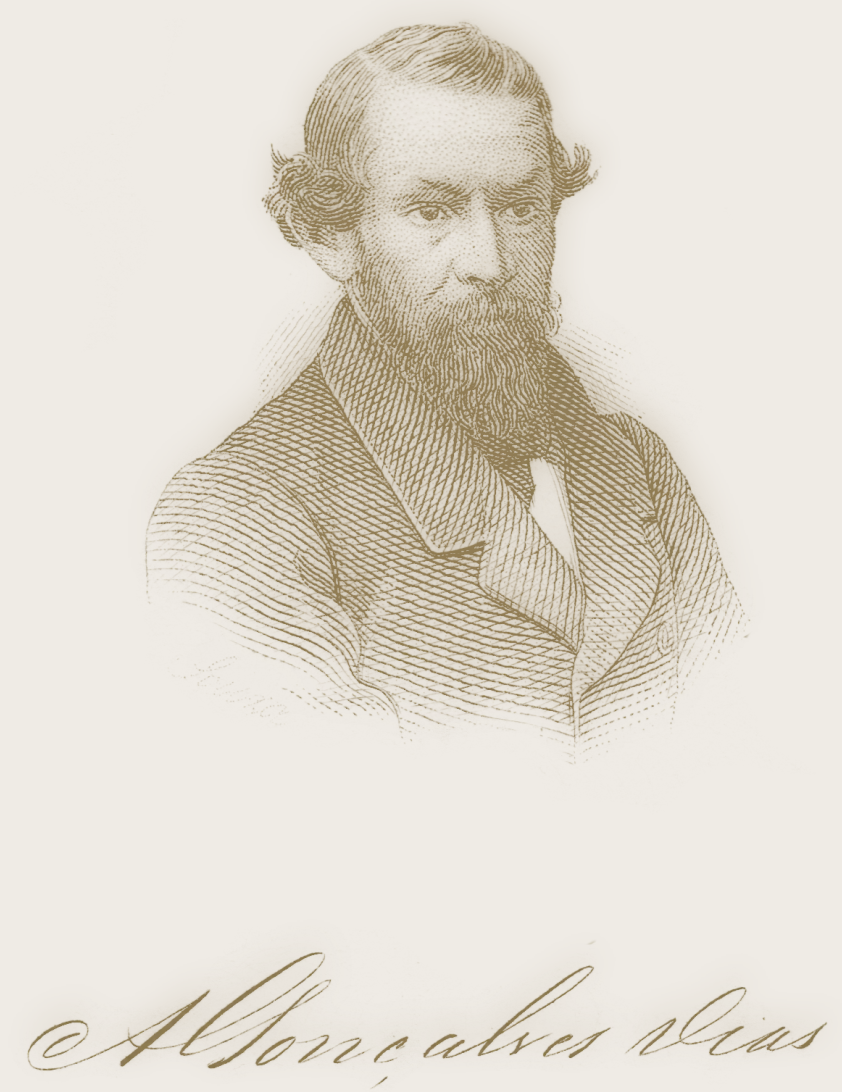

Retrato de António Gonçalves Dias, aluno da Universidade de Coimbra, entre 1840 e 1845.

Rara água-forte com representação tardia do poeta, barba comprida serrada, extraída do Novo Almanach de Lembranças Luzo-brazileiro para o anno de 1873.

Assinado "Souza", Joaquim Pedro de Sousa (1818-1878).

BGUC: Col. de Estampas. Pasta 5, no 3 


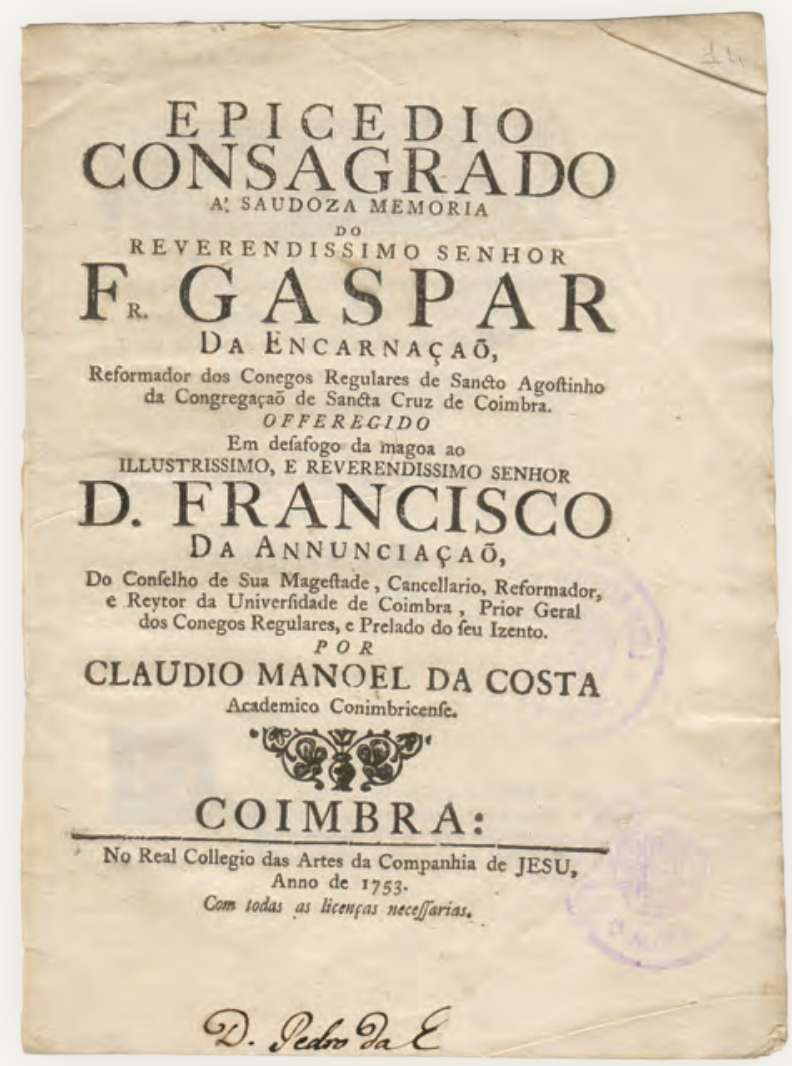

Costa, Cláudio Manuel da, 1729-1789 - Epicedio consagrado à saudoza memoria do Reverendissimo Senhor Fr. Gaspar da Encarnaçaô, reformador dos Conegos Regulares de Sancto Agostinho da Congregaçaõ de Sancta Cruz de Coimbra ... Coimbra: no Real

Collegio das Artes da Companhia de Jesus, 1753. BGUC: J.F.-43-3 A-1 (14) 



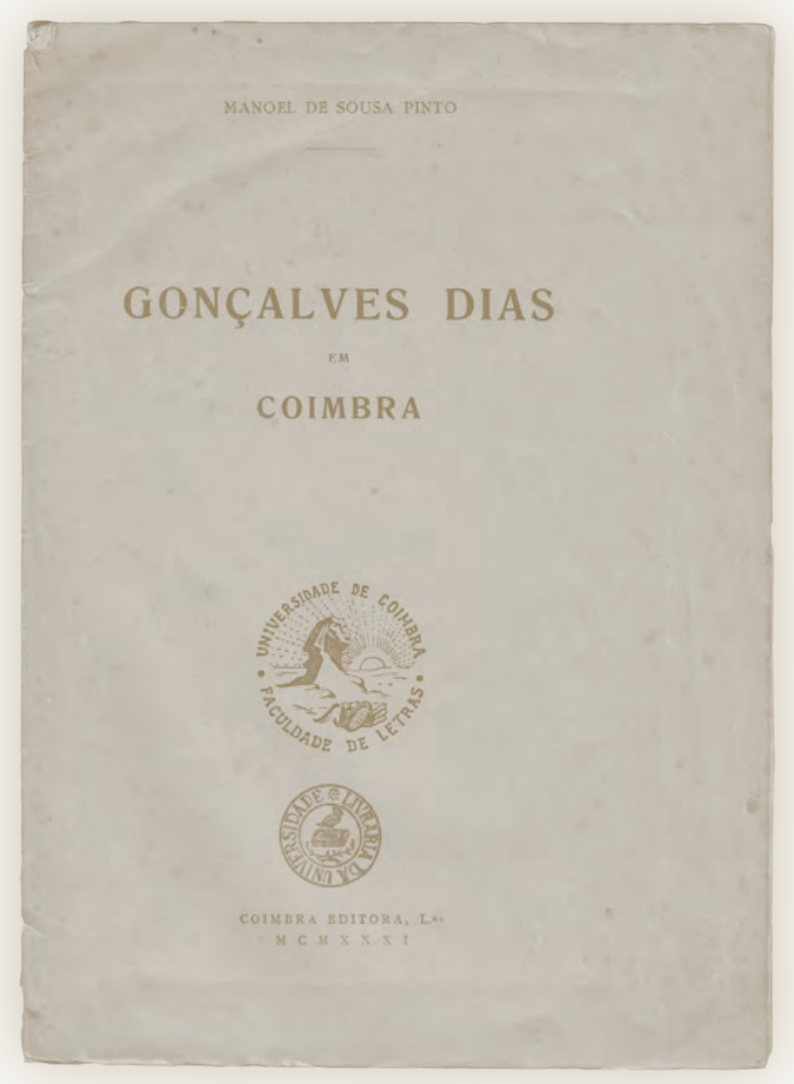

Pinto, Manuel de Sousa, 1880-1934 -

Gonçalves Dias em Coimbra. Coimbra: Coimbra

Ed., 1931. 17 p. Sep. de: Biblos, 1931. BGUC: O.S. 712 


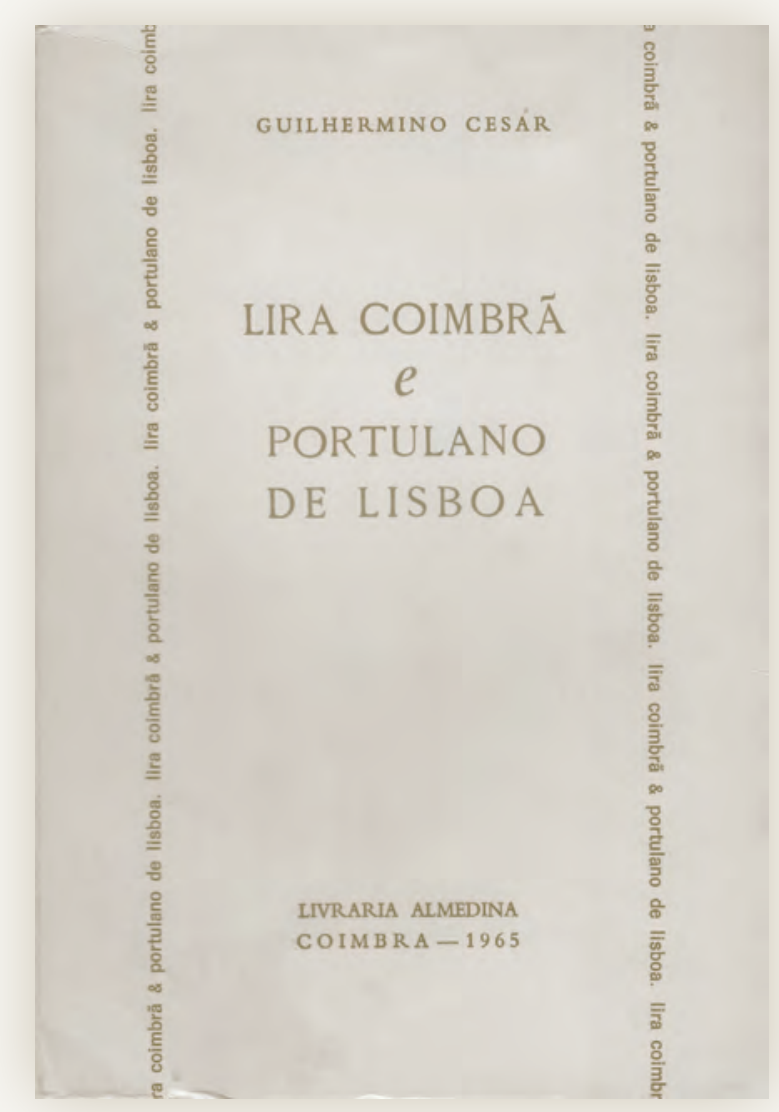

César, Guilhermino, 1908-1993 - Lira coimbrã e portulano de Lisboa. Coimbra: Livraria Almedina, 1965.

BGUC: 5-12-22-37 
